\title{
Involvement of the Src-cortactin pathway in migration induced by IGF-1 and EGF in human breast cancer cells
}

\author{
SILVIA MEZI ${ }^{1}$, LAURA TODI $^{2}$, ERRICO ORSI $^{3}$, ANTONIO ANGELONI $^{4}$ and PATRIZIA MANCINI ${ }^{2}$ \\ ${ }^{1}$ Department of Radiology, Oncology and Human Pathology, Division of Oncology B, \\ ${ }^{2}$ Department of Experimental Medicine, ${ }^{3}$ Department of Surgical Science, Division of DEA, \\ ${ }^{4}$ Department of Molecular Medicine, Sapienza University of Rome, Rome, Italy
}

Received June 21, 2012; Accepted July 30, 2012

DOI: $10.3892 /$ ijo.2012.1642

\begin{abstract}
Cancer cells need to become motile in order to escape the primary tumor and move to distant areas to form metastasis. They move as single cells or as a group, following different stimuli, including growth factors. Among them, insulin-like growth factor-1 (IGF-1) and epidermal growth factor (EGF) and their receptors have been implicated in the development and progression of human breast carcinoma. In this report, we provide evidence that the tyrosine kinase Src is responsible for migration promoted by both IGF-1 and EGF in MDA-MB-231 and MCF7 cells, although with a different effect. Moreover, both IGF-1 and EGF induce reorganization of actin cytoskeleton in lamellipodia and membrane ruffles in a time- and Src-dependent manner. Furthermore, we analyzed the tyrosine phosphorylation status of the actin-binding protein cortactin upon growth factor stimulation, showing that even the activation of cortactin is time- and Src-dependent. In addition, immunofluorescence analysis with anti-paxillin antibody reveals that, after treatment with growth factors, tyrosine phosphorylated cortactin is localized on the plasma membrane in correspondence of focal adhesions. Collectively, our findings suggest a crucial role for Src-mediated activation of cortactin in cell migration, reorganization of actin cytoskeleton and phosphotyrosine cortactin localization to the focal adhesions in human breast cancer cell lines upon both IGF-1 and EGF stimulation.
\end{abstract}

\section{Introduction}

Metastasis is a complex process characterized by the detachment of cells from the primary tumor followed by their dissemination into surrounding tissues to form secondary tumors at distant sites, which is the most common cause

Correspondence to: Dr Patrizia Mancini, Department of Experimental Medicine, Viale Regina Elena 324, I-00161 Rome, Italy

E-mail: patrizia.mancini@uniroma1.it

Key words: cell migration, actin cytoskeleton, cortactin, Src, insulin-like growth factor-1, epidermal growth factor of death for cancer patients (1). Several types of molecules are involved in the metastatic process, including adhesion molecules, such as cadherins and integrins, various metalloproteases, as well as growth factors and their receptors (2). Cancer cells need to be motile in order to escape the tumor mass to form metastasis. They move in different ways: as a group or as single cells, adopting an elongated phenotype or moving in an ameboid shape (1), depending on the organization of actin cytoskeleton. Among a variety of molecules involved in cell migration, cortactin plays a pivotal role. Discovered as a Src kinase substrate in RSV-transformed fibroblasts (3), cortactin is a multidomain actin-binding protein $(4,5)$. The N-terminal half of the molecule includes the acidic domain (NTA), responsible for the interaction with the Arp2/3 complex, and a tandem repeats containing the $\mathrm{F}$-actin binding site. The $\mathrm{C}$-terminal half is composed by an $\alpha$-helical region, followed by a region rich in proline, serine and threonine, which harbors critical tyrosine residues, and finally an Src-homology 3 (SH3) domain (6). Cortactin is enriched at membrane ruffles and lamellipodia of several different cell types (4), and plays a crucial role in regulating membrane dynamics and actin assembly for the control of membrane movements (5). Furthermore, cortactin is reported to be overexpressed in many different tumor types. The cortactin gene EMS1, located on chromosome 11q13, is amplified in numerous human carcinomas (7) and is usually correlated with poor patient prognosis (8). Moreover, cortactin can be activated by phosphorylation of tyrosines in position 421, 466 and 482 by Src kinase after many different stimuli (9).

These properties of cortactin prompted us to examine its role in cell migration promoted by insulin-like growth factor-1 (IGF-1), one of the component of the IGF system, and the epidermal growth factor (EGF) in human breast cancer cell lines.

Previous studies have demostrated that IGF-1 is a physiological peptide, whose biological function is carried out following binding to its specific receptor (IGF-1R), a ubiquitous and multifunctional tyrosine kinase receptor (2). Overexpression and activity of IGF-1R have been associated with many different types of tumors, such as breast, prostate, lung, colon and head and neck squamous cell carcinoma (10). The IGF-1R is overexpressed in estrogen receptor (ER)-positive cells. These data are prominent because IGF-1R has been implicated in different growth-related and growth-unrelated processes, critical for the development and progression of malignant tumors, such 
as proliferation, survival, and anchorage-independent growth, as well as cell adhesion, migration and invasion $(11,12)$. The activation of the IGF-1R pathway promotes cell growth and counteracts the anticancer-induced apoptosis. Nevertheless, ER-negative tumors and cell lines, often exhibiting less differentiated, mesenchymal-like phenotypes, express low levels of IGF-1R $(11,13,14)$. Notably, these cells do not respond to IGF-1 with growth $(11,15-18)$. The lack of IGF-1R pathway activation impaired the metastatic potential of ER-negative breast cancer cells by inhibiting both mitogenic response and migration in vitro and tumorigenesis in vivo (19-21). The epidermal growth factor receptor (EGFR) is involved in various aspects of cell growth, survival, differentiation, migration and invasion $(22,23)$. EGFR is overexpressed in MDA-MB-231 breast cancer cells, although the event is not due to gene amplification (24), while MCF7 breast cancer cells lack EGFR-overexpression (25).

Here we analyzed the effect of IGF-1 and EGF on the epidermal growth factor receptor-2 (ERB-B2) negative human invasive ductal breast carcinoma cell lines, MDA-MB-231 and MCF7 (26). The two cell lines differ in several cytological and biochemical parameters: MCF7 cells possess a functional ER, have an epithelial-like morphology and grow in colonies, whereas MDA-MB-231 cells are (ER)-negative and progesterone receptor $(\mathrm{PgR})$-negative and show a mesenchymal-like morphology and grow as a monostrate. Furthermore, MDA-MB-231 cells exhibit strong invasive and metastatic capacities, and are representative of cells in late-stage breast cancer, while MCF7 are a poorly invasive and non-metastatic breast cancer cell line (27). MCF7 have a characteristic luminal epithelial profile $(27,28)$, conversely MDA-MB-231 shows a gene expression pattern similar to the claudin-low tumor subtype with the lowest expression of genes involved in epithelial cell-cell adhesion (i.e., E-cadherin and claudins 3, 4 and 7) vs the other breast cancer phenotypes, low luminal differentiation (i.e., CD24, EpCAM), and high values for the CD44/CD24 and CD49f/EpCAM mRNA ratios (29), and poor prognosis.

The present study investigates the mechanism underlying the IGF-1 mediated migration of human HER2 negative breast cancer cells, and all the experiments were performed comparing the results obtained by using IGF-1 with those obtained by EGF. We demonstrate that both growth factors mediate: i) the motogenic effect on the two cell lines, with a stronger effect of IGF-1 on the claudin-low cell line, ii) the actin cytoskeletal organization in typical migratory structures, iii) the translocation of the phospho-Y421-cortactin to the focal adhesions, and we show that all these processes are Src-dependent.

\section{Materials and methods}

Materials. Human recombinant epidermal growth factor (EGF) and human recombinant insulin-like growth factor type-1 (IGF1), TRITC-phalloidin, anti-tubulin monoclonal antibody, and anti-mouse IgG peroxidase antibodies were purchased from Sigma (St. Louis, MO, USA). Goat anti-rabbit IgG peroxidase antibody was from Amersham Biosciences (Uppsala, Sweden). Anti-cortactin polyclonal antibodies were from Santa Cruz Biotechnology (Santa Cruz, CA, USA) and mouse anti-paxillin monoclonal antibody was obtained from BD Pharmingen (San Diego, CA, USA). Anti-phosphotyrosine monoclonal antibody (clone 4G10) and anti-cortactin monoclonal antibody (clone
4F11) were purchased from Upstate Biotechnology (Lake Placid, NY, USA). Anti-phospho-cortactin pY421 polyclonal antibodies were purchased from Invitrogen (Carlsband, CA, USA). FITCconjugated goat anti-rabbit IgG was obtained from Cappel Research Products (Durham, NC, USA), Texas Red-conjugated goat anti-mouse IgG was from Jackson Immunoresearch Laboratories (West Grove, PA, USA). Src inhibitor SU6656 was obtained from Calbiochem (San Diego, CA, USA).

Cell lines and treatments. The human breast cancer cell lines MDA-MB-231 and MCF7 were cultured in Dulbecco's modified Eagle's medium (DMEM, Euroclone, Pero, Italy) supplemented with $10 \%$ fetal bovine serum and antibiotics. For inhibition of Src specific family protein tyrosine kinases, cells were preincubated with SU6656 (30), $5 \mu \mathrm{M}$ for $1 \mathrm{~h}$, before incubation with IGF-1 or EGF in the presence of the same inhibitor at $37^{\circ} \mathrm{C}$ in pre-warmed medium.

Scratch assay. MDA-MB-231 and MCF7 cells were seeded at $5 \times 10^{5}$ and $1.2 \times 10^{6}$ cells on $35-\mathrm{mm}$ plates, respectively, and grown until confluence. Confluent cells were serum starved for $12 \mathrm{~h}$ and then a standardized cell-free area was introduced by scraping the monolayer with a sterile tip. After intensive washing, the remaining cells were incubated for $24 \mathrm{~h}$ in the presence of IGF-1 $(10 \mathrm{ng} / \mathrm{ml})$ or EGF $(50 \mathrm{ng} / \mathrm{ml})$. After incubation, the cells were fixed with $4 \%$ paraformaldehyde for $30 \mathrm{~min}$ at $25^{\circ} \mathrm{C}$ and photographs were taken using an AxioObserver inverted microscope (Carl Zeiss Inc.). Some plates were fixed and photographed immediately after scratching, representing a T0 control. For inhibition of Src family protein tyrosine kinases, cells were preincubated with SU6656 $(5 \mu \mathrm{M})$ for $1 \mathrm{~h}$ before stimulation with the growth factors. The effects of growth factors and inhibitor on cell migration was evaluated by measuring the distance remaining between the two sides of the scratch area, performed using Axio Vision software (Carl Zeiss Inc.). The data presented are a mean of triplicate experiments \pm SEM. Statistical analysis was carried out using Student's t-test to evaluate significative differences with respect to control.

Immunofluorescence microscopy. MDA-MB-231 and MCF7 cells, grown on coverslips, were treated with IGF-1 or EGF for 10, 30 or $60 \mathrm{~min}$, or pre-incubated with the Src inhibitor SU6656 for $1 \mathrm{~h}$ before adding the growth factors, as above. Cells were subsequently fixed in $4 \%$ paraformaldehyde in phosphate-buffered saline (PBS) for $30 \mathrm{~min}$ at $25^{\circ} \mathrm{C}$, followed by treatment with $0.1 \mathrm{M}$ glycine in PBS for $20 \mathrm{~min}$ at $25^{\circ} \mathrm{C}$ and with $0.1 \%$ Triton $\mathrm{X}-100$ in PBS for additional $5 \mathrm{~min}$ at $25^{\circ} \mathrm{C}$ to allow permeabilization. Cells were then incubated for $1 \mathrm{~h}$ at $25^{\circ} \mathrm{C}$ with the following primary antibodies: anti-cortactin polyclonal antibodies (1:100 in PBS), anti-cortactin monoclonal antiboby (1:100 in PBS), anti-paxillin monoclonal antibody (1:100 in PBS) and anti-phospho-cortactin pY421 polyclonal antibodies (1:100 in PBS). The primary antibodies were visualized, after appropriate washing in PBS, using FITC-conjugated goat anti-rabbit IgG (1:100 in PBS) or Texas Red-conjugated goat anti-mouse IgG (1:50 in PBS). Actin cytoskeleton was visualized using TRITC-phalloidin (1:50) for $45 \mathrm{~min}$ at $25^{\circ} \mathrm{C}$. Coverslips were finally mounted with mowiol for observation. Fluorescence signal was analyzed by recording stained images using an AxioObserver inverted microscope, equipped with the ApoTome System (Carl Zeiss Inc.). 
Immunoprecipitation and western blot analysis. Subconfluent cultures of MDA-MB-231 and MCF7 cells, treated with IGF-1 or EGF and SU6656, as above, were lysed in a buffer containing $50 \mathrm{mM}$ Tris- $\mathrm{HCl} \mathrm{pH} 7.4,150 \mathrm{mM} \mathrm{NaCl}, 1 \% \mathrm{NP}-40$, $1 \mathrm{mM}$ EDTA, supplemented with protease inhibitors $(10 \mu \mathrm{g} / \mathrm{ml}$ aprotinin, $10 \mu \mathrm{g} / \mathrm{ml}$ leupeptin, $2 \mathrm{mM}$ PMSF), and phosphatase inhibitors ( $1 \mathrm{mM}$ sodium orthovanadate, $20 \mathrm{mM}$ sodium pyrophosphate, $50 \mathrm{mM}$ sodium fluoride). Total protein $(50 \mu \mathrm{g})$ was resolved under reducing conditions by $8 \%$ SDS-PAGE and transferred to reinforced nitrocellulose (Protran, Schleider and Schuell, Keene, NH, USA). The membrane was blocked with $5 \%$ non-fat dry milk in PBS $0.1 \%$ Tween-20, and incubated with anti-cortactin polyclonal antibodies diluted 1:1,000, followed by enhanced chemiluminescence detection (ECL). For the equal loading, the membrane was probed with anti-tubulin monoclonal antibody. For immunoprecipitation experiments, $1 \mathrm{mg}$ of total protein from cell lysates, prepared as above, was incubated with $4 \mu \mathrm{g} / \mathrm{ml}$ anti-cortactin polyclonal antibodies. Immunocomplexes, aggregated with $50 \mu \mathrm{l}$ of $\gamma$-bind protein-G sepharose (Amersham Biosciences), were washed four times with $0.5 \mathrm{ml}$ of buffer. The pellets were boiled in Laemmli buffer for $5 \mathrm{~min}$, and the protein resolved under reducing conditions by $8 \%$ SDS-PAGE and transferred to reinforced nitrocellulose (Protran). The membranes were blocked with 5\% non-fat dry milk in PBS $0.1 \%$ Tween-20 and incubated with anti-phosphotyrosine monoclonal antibody diluted 1:1,000 for $1 \mathrm{~h}$ at $25^{\circ} \mathrm{C}$, followed by goat anti-mouse-HRP secondary antibody and enhanced chemiluminescence detection (ECL, Amersham Biosciences, Arlington Heights, IL, USA). To estimate the protein equal loading, the membranes were rehydrated by being washed in PBS Tween-20, stripped with $100 \mathrm{mM}$ mercaptoethanol and $2 \%$ SDS for $30 \mathrm{~min}$ at $55^{\circ} \mathrm{C}$, and then reprobed with anti-cortactin polyclonal antibodies diluted 1:1,000. Densitometric analysis was performed using Image J software. The signal intensity for each band was calculated and the background subtracted from experimental values. The resulting values were then normalized, expressed as fold increase with respect to the control value and visualized as a graph.

\section{Results}

IGF-1 induces migration of breast cancercells in a Src-dependent manner. In order to assess the motogenic effect of IGF-1 on human breast cancer cells, we analyzed cell migration through scratch assay. To this aim, MDA-MB-231 and MCF7 cells were seeded onto Petri dishes and allowed to grow to confluence. Then, a cell-free area was introduced in monolayers and cells were allowed to migrate from the edge of the scratch for $24 \mathrm{~h}$ in the presence of IGF-1. To better evaluate the effect of IGF-1, we used EGF as positive control for migration, as this growth factor has been shown to be strongly motogenic for cancer cell lines $(31,32)$. As shown in Fig. 1, IGF-1 displayed a stronger migratory effect on MDA-MB-231 cells compared to MCF7. On the other hand, EGF treatment induced a more evident migration on MCF7 with respect to MDA-MB-231 (Fig. 1). Moreover, both the growth factors induced significant migration with respect to control untreated cells (Fig. 1).

Since the protein tyrosine kinase Src has been previously shown to be involved in cell motility (33), to evaluate the potential role of Src in regulating the migratory effect of IGF-1 and EGF on MDA-MB-231 and MCF7 cells, we performed the scratch assay, as above, in the presence of the selective Src family protein tyrosine kinase inhibitor, SU6656 (30). Treatment with SU6656 was able to significantly prevent the migration of both the cancer cell lines upon either IGF-1 and EGF stimulation (Fig. 1), thus suggesting the involvement of Src in this process. Taken together, these data indicate that both IGF-1 and EGF stimulate migration of human cancer cells and strongly suggest a crucial role of Src in this process.

IGF-1 differentially affects migratory phenotype and actin reorganization in MDA-MB-231 and MCF7 cells. Since the actin cytoskeleton reorganization in lamellipodia and membrane ruffles is a crucial step for cells to migrate (34), here we analyzed the reorganization of actin cytoskeleton in human breast cancer cells upon IGF-1 treatment. To this purpose, starved MDA-MB-231 and MCF7 cells were stimulated with IGF-1 or EGF at different time points, and stained with TRITC-phalloidin, that specifically recognizes filamentous actin cytoskeleton. Immunofluorescence analysis revealed that untreated MDA-MB-231 cells exhibited a polygonal, enlarged and flat shape, with actin cytoskeleton mainly organized in stress fibers (Fig. 2, arrows, upper left panel), as previously described (35). Upon treatment with IGF-1, MDA-MB-231 cells showed actin reorganization in membrane ruffles and lamellipodia already after $10 \mathrm{~min}$ (Fig. 2, arrowheads, left panels), which were still present at 30 and 60 min (Fig. 2, arrowheads, left panels), althought after $60 \mathrm{~min}$ of treatment with IGF-1 some stress fibers were also evident (Fig. 2, arrow, left panels). Moreover, cells displayed an elongated shape, which is the typical phenotype of migrating cells (Fig. 2, left panels). In contrast, the actin cytoskeleton organization in membrane ruffles and lamellipodia was evident after 30 and 60 min of stimulation with EGF (Fig. 2, arrowheads, left panels). whereas, after 10 min the actin cytoskeleton was organized mainly in stress fibers (Fig. 2, arrows, left panels) and in some small lamellipodia and ruffles (Fig. 2, arrowheads, left panels). Furthermore, cells displayed phenotype that changes depending on time of treatment with EGF, being polygonal at $10 \mathrm{~min}$, and elongated at 30 and $60 \mathrm{~min}$ of stimulation, showing a clear leading edge (Fig. 2, left panels). In the case of MCF7, we focused our attention on cells that are localized at the periphery of colonies, because they are the ones that undergo migration. Untreated MCF7 showed clearly separated colonies with regular edges, and the actin mainly organized in well defined stress fibers (Fig. 2, arrows, upper right panel). Upon IGF-1 treatment, MCF7 cells showed the actin cytoskeleton organized in membrane ruffles and lamellipodia, more evident at 30 and $60 \mathrm{~min}$ of stimulation, and only partially at $10 \mathrm{~min}$ (Fig. 2, arrowheads, left panels). The treatment with EGF induced reorganization of actin cytoskeleton in membrane ruffles and lamellipodia already after $10 \mathrm{~min}$, which were less evident at 30 and 60 min of stimulation (Fig. 2, arrowheads, left panels). Interestingly, in MCF7 cells both IGF-1 and EGF induce reorganization of actin in a large array of lamellipodia, which remain confined throughout the cell cluster and do not extend beyond the edges of the cell colonies (Fig. 2, left panels). Moreover, after stimulation of both growth factors, cells at the periphery of MCF7 clusters showed a partially elongated cell shape, typical of cells that are separating from the colony (Fig. 2, left panels). Thus, a migratory phenotype was achieved by breast carcinoma cells after stimulation with both growth factors, but at different time points. To evaluate if the actin 
MDA-MB-231
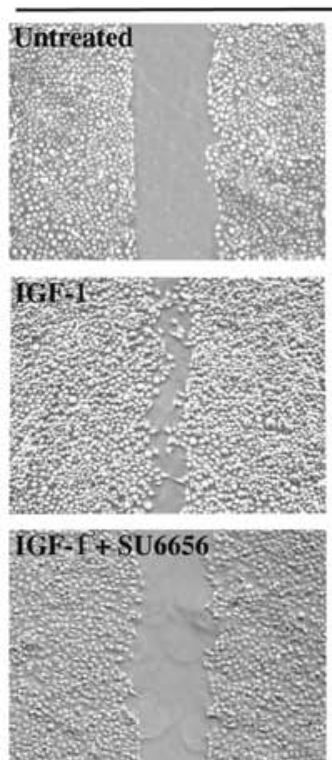
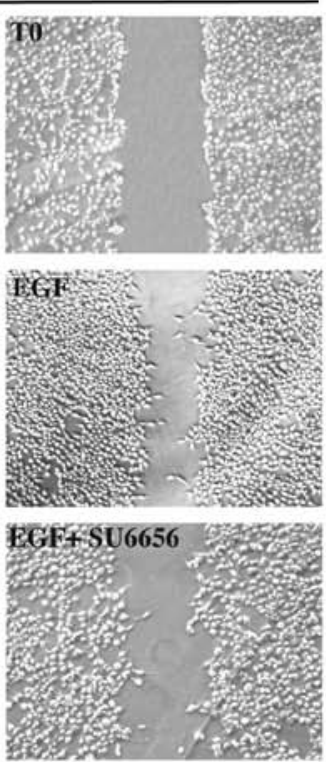

MCF7

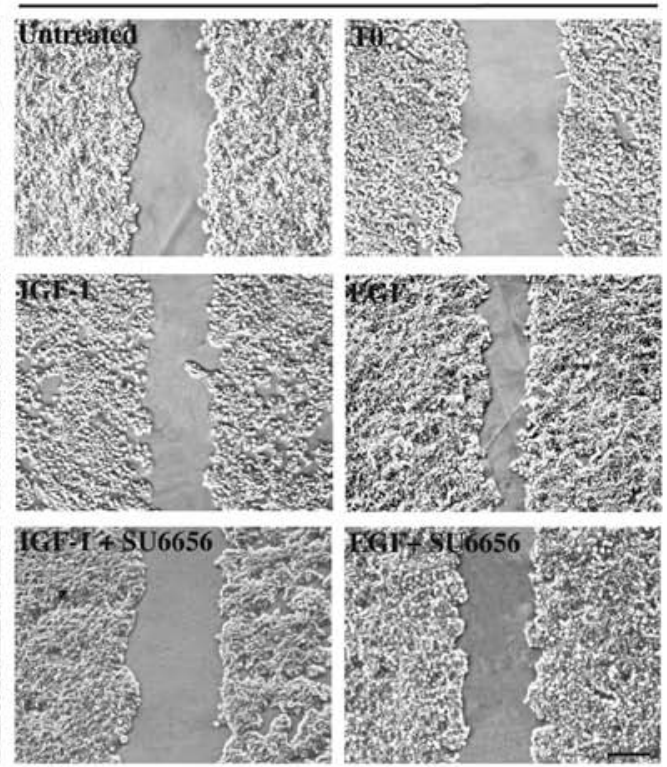

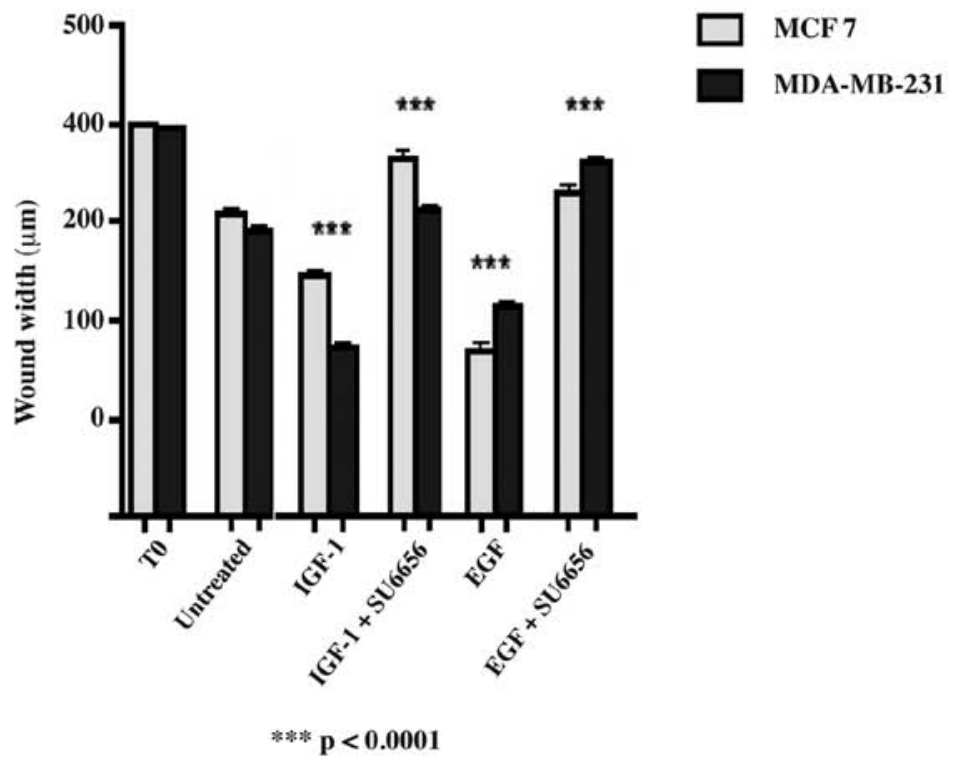

Figure 1. IGF-1 induces cell migration on human breast cancer cells in an Src-dependent manner. MDA-MB-231 and MCF7 cells were seeded onto Petri dishes and allowed to grow until confluence. A cell-free area was introduced in monolayers, and then cells were immediately fixed (T0) or allowed to migrate from the edge of the scratch for $24 \mathrm{~h}$ at $37^{\circ} \mathrm{C}$ in the presence or not of IGF-1 or EGF. IGF-1 stimulation induces a more evident cell migration on MDA-MB-231 cells than on MCF7, while EGF is more motogenic on MCF7 with respect to MDA-MB-231. Treatment with SU6656 inhibits migration of both cancer cell lines upon either IGF-1 and EGF stimulation, strongly suggesting the involvement of Src in this process. The images are representative of three independent experiments. Bar, $200 \mu \mathrm{m}$. Cell migration was quantified measuring the mean gap distance between the edges of the scratch area as reported in Materials and methods. Student's t-test was performed and significant differences are reported $(* * * 0.0001)$.

cytoskeleton reorganization in the cell lines that we assayed is dependent on Src activation, we performed parallel experiments in the presence of the Src inhibitor SU6656. Results showed that SU6656 prevented both the migratory phenotype and the formation of membrane ruffles and lamellipodia on MDA-MB-231 and MCF7 cells (Fig. 2, right panels). Taken together, these results suggest that IGF-1 and EGF are able to induce actin reorganization in human carcinoma cell lines, although the effect of IGF-1 was more rapid and consistent in MDA-MB-231 than in MCF7 cells, and that this process is Src-dependent.
IGF-1 induces rapid tyrosine phosphorylation of cortactin in breast cancer cells. Since one of the molecules involved in the reorganization of actin cytoskeleton is cortactin, an actin-binding protein, whose activity depends on tyrosine phosporylation mediated by the tyrosine kinase Src (6), we evaluated the possible involvement of cortactin in human breast carcinoma cells upon IGF-1 stimulation. To this purpose, we first determined the expression of cortactin in MDA-MB-231 and MCF7 cells by western blot analysis. Cells were lysed and blotted with anti-cortactin antibodies, and the membrane was 

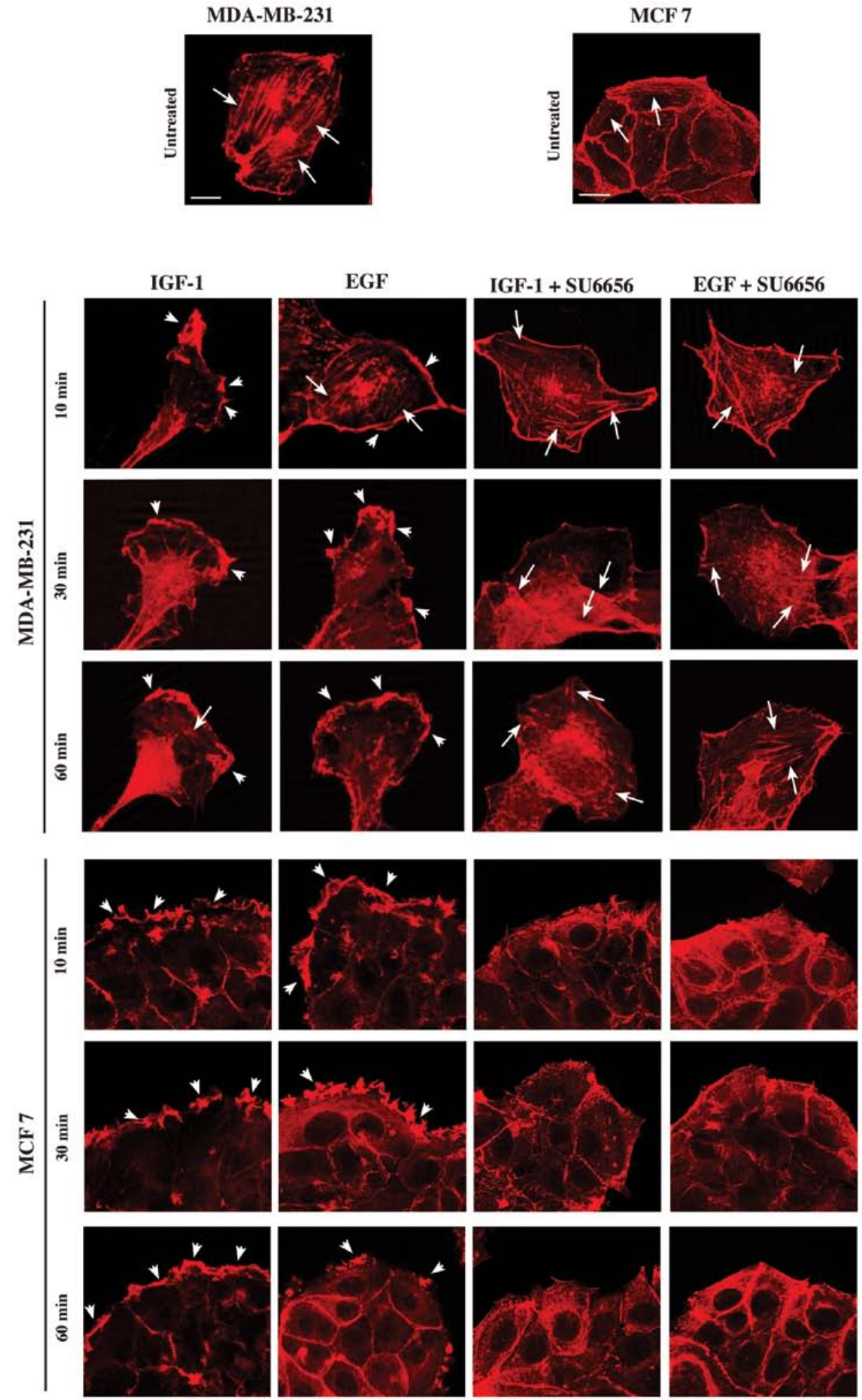

\section{EGF + SU6656}
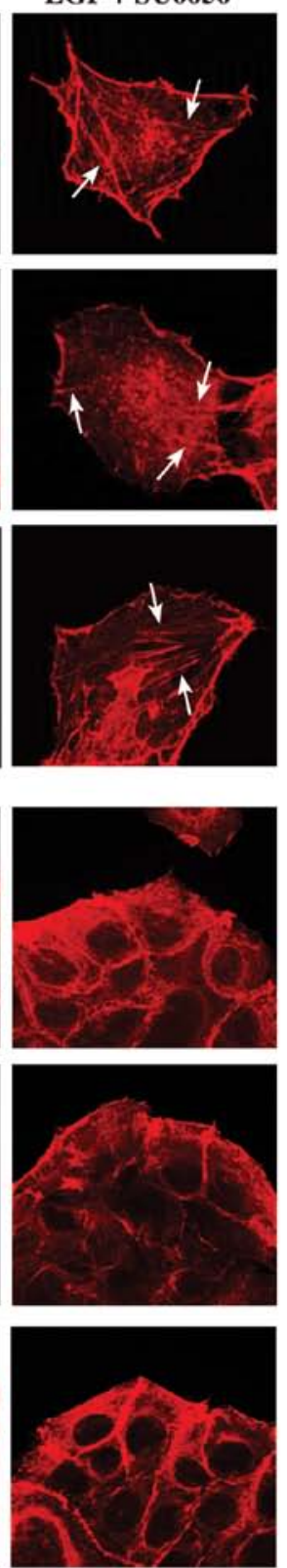

Figure 2. IGF-1 induces actin cytoskeleton reorganization and migratory phenotype on the two breast cancer cell lines in a different manner. MDA-MB-231 and MCF7 cells were stimulated with IGF-1 or EGF at 10,30 and $60 \mathrm{~min}$, fixed, permeabilized and stained with TRITC-phalloidin to visualize the actin cytoskeleton organization. Untreated MDA-MB-231 cells show a polygonal cell shape, with actin cytoskeleton mainly organized in stress fibers (arrows). In MDA-MB-231, IGF-1 induces actin organization in membrane ruffles and lamellipodia already after $10 \mathrm{~min}$ of stimulation (arrowheads), still present at 30 and 60 min, during which some stress fibers are also evident (arrow). Moreover, cells display a typical migratory phenotype. After 10 min of stimulation with EGF, actin cytoskeleton is organized mainly in stress fibers (arrows) and in membrane ruffles and lamellipodia after $30 \mathrm{~min}$ (arrowheads), which were more evident at 60 min (arrowheads). Furthermore, cells show a phenotype that changed depending on the time of stimulation, being at 10 min polygonal, and elongated at 30 and 60 min. Untreated MCF7 show clearly separated colonies with regular edges, and the actin mainly organized in well defined stress fibers (arrows). Upon IGF-1 stimulation, MCF7 cells display actin organized in membrane ruffles and lamellipodia, especially evident after 30 and 60 min of stimulation, and only partially at 10 min (arrowheads). The treatment with EGF promotes formation of membrane ruffles and lamellipodia already after $10 \mathrm{~min}$, which are less evident at 30 and 60 min (arrowheads). After stimulation of both growth factors, cells at the periphery of MCF7 clusters display a partially elongated cell shape, typical of cells that are separating from the colony. In addition, in the presence of the Src inhibitor SU6656 the formation of membrane ruffles and lamellipodia on either MDA-MB-231 and MCF7 cells was prevented, and the cells do not achieve a migratory phenotype. The images are representative of three independent experiments. Bars, $10 \mu \mathrm{m}$. 
A

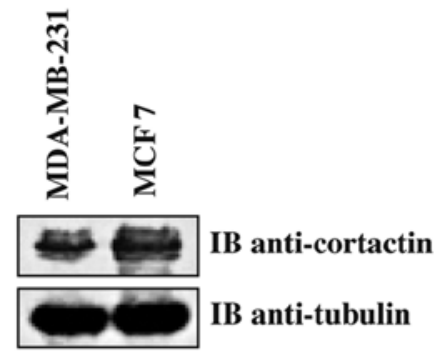

B

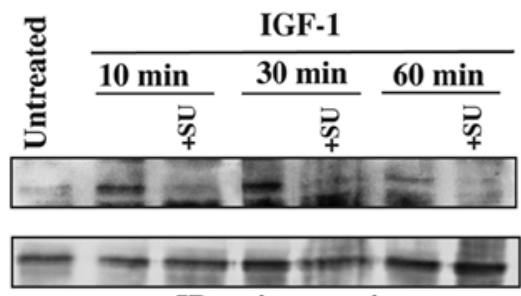

IP anti-cortactin

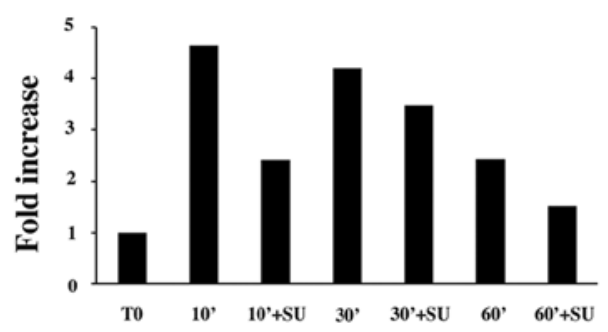

C
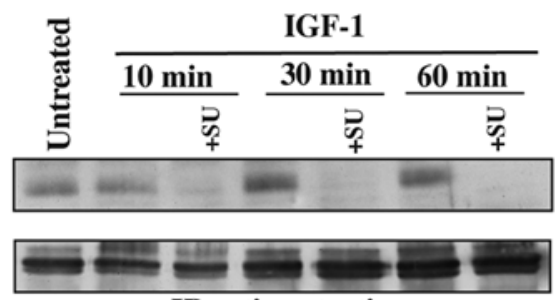

IP anti-cortactin

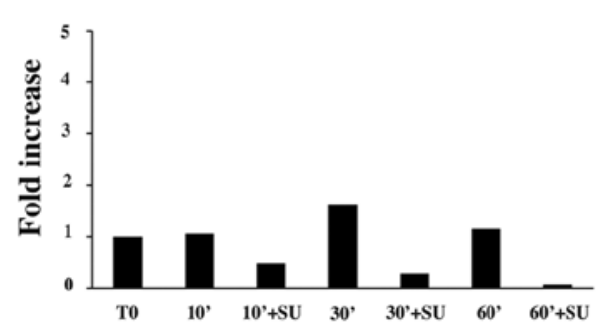

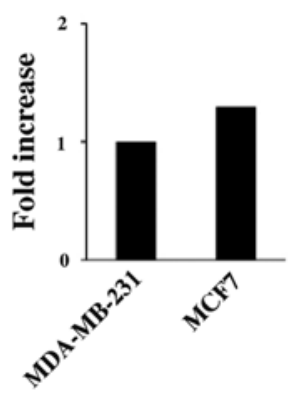

IB anti-PY

IB anti-cortactin
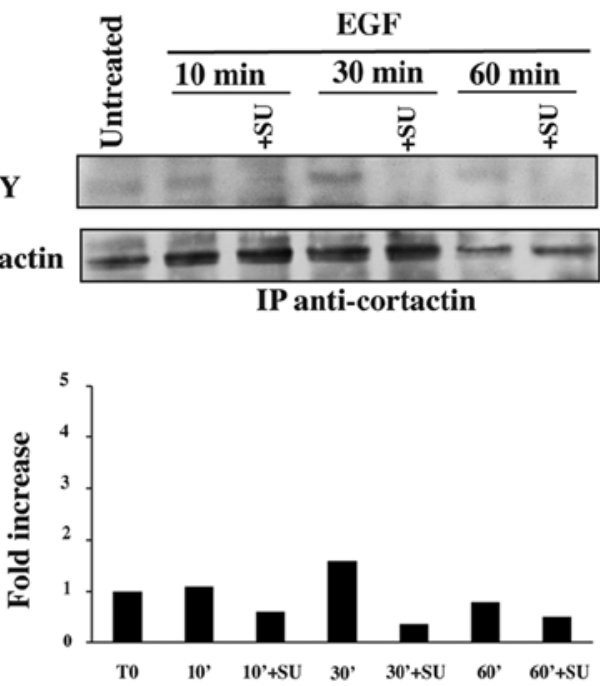

IB anti-PY

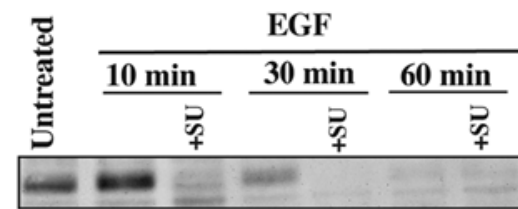

IB anti-cortactin

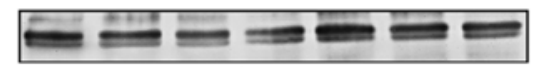

IP anti-cortactin

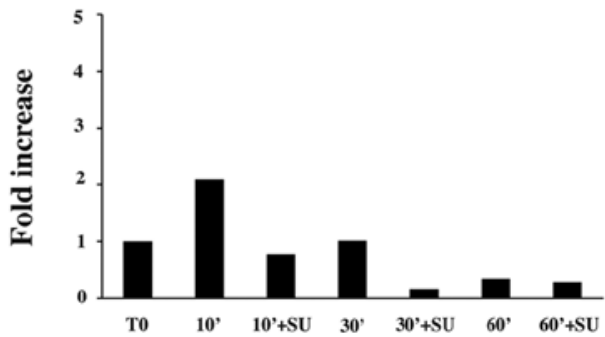

Figure 3. IGF-1 induces tyrosine phosphorylation of cortactin. (A) Expression of cortactin in MDA-MB-231 and MCF7 cells by western blot analysis. Cells were lysed and blotted with anti-cortactin antibodies and the membrane was subsequently stripped and blotted with anti- $\alpha$-tubulin antibody to assess the equal loading. A band corresponding to the protein cortactin is present in both the cell lines, although the amount of the protein expressed by MCF7 cells is greater than that exhibited by MDA-MB-231. Biochemical study of cortactin tyrosine phosphorylation in serum starved (B) MDA-MB-231 and (C) MCF7. Cells were treated with IGF-1 or EGF at different time points, immunoprecipitated with anti-cortactin antibodies and immunoblotted with anti-phosphotyrosine antibody. In MDA-MB-231 cells (B), IGF-1 stimulation induces a strong intensity level of tyrosine phosphorylation of cortactin already evident after 10 min and still present at 30 and $60 \mathrm{~min}$. Whereas, EGF stimulation promotes a lower intensity of tyrosine phosphorylation of cortactin, with a peak after 30 min of treatment. In the case of MCF7 cells (C), the highest point of the phosphorylation of the protein is found after $30 \mathrm{~min}$ of treatment with IGF-1, still present at 60 min, whereas, the treatment with EGF induces a good activation of cortactin already after $10 \mathrm{~min}$, which decreases at $30 \mathrm{~min}$ and is virtually absent after $60 \mathrm{~min}$ of stimulation. The membranes were subsequently stripped and blotted with anti-cortactin antibodies to assess the equal loading. Parallel experiments performed in the presence of SU6656, show that the Src inhibitor blocks tyrosine phosphorylation of cortactin (B and C). The intensity of the bands was evaluated by densitometric analysis; the values from a representative experiment were normalized, expressed as fold increase with respect to the control value and reported as a graph (A-C). 

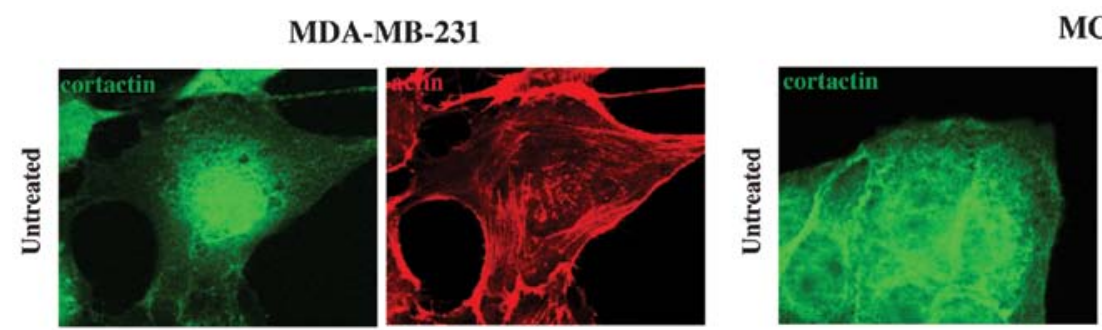

MCF7
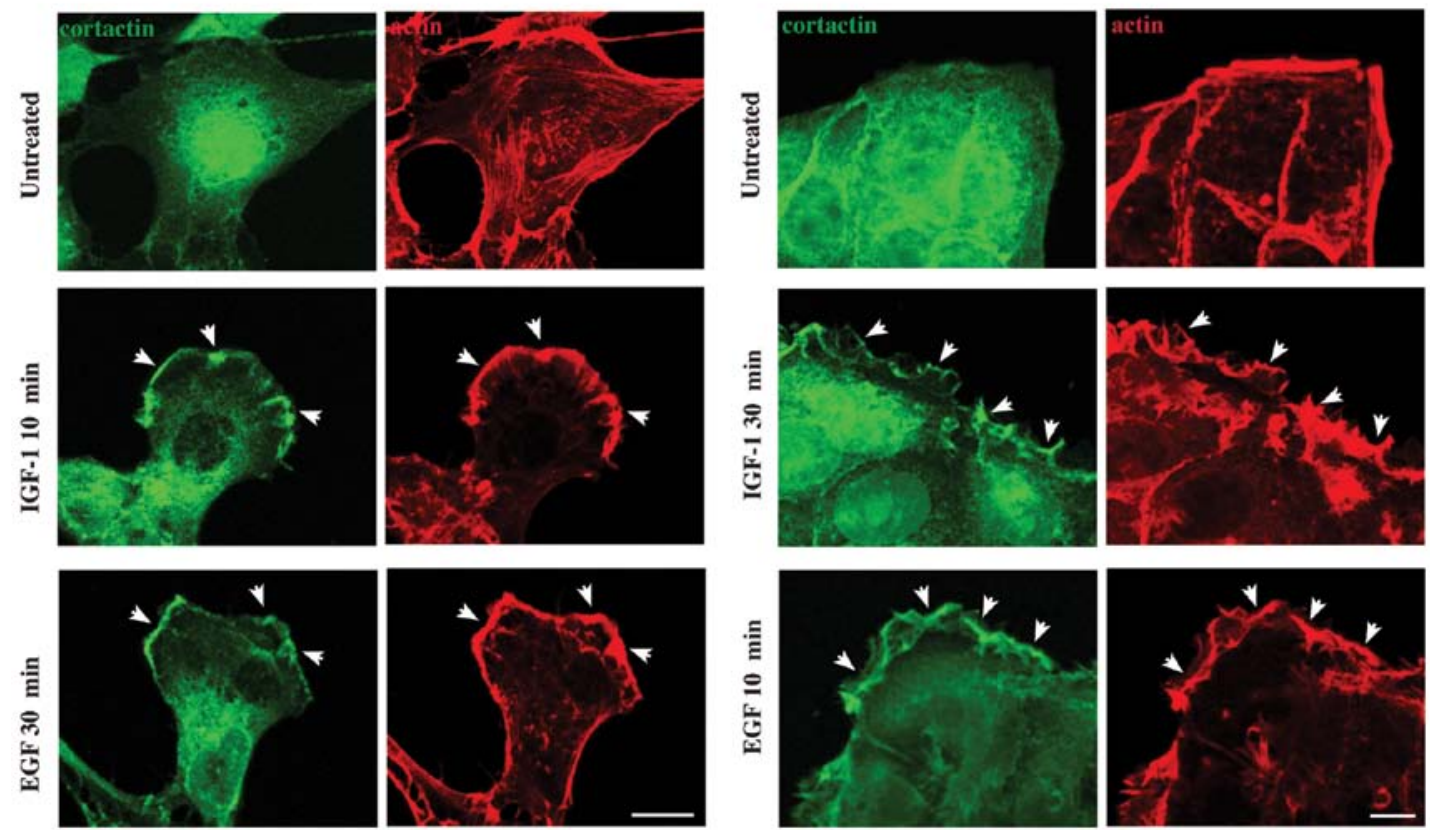

Figure 4. IGF-1 promotes cortactin traslocation to the plasma membrane. MDA-MB-231 and MCF7 cells were treated with IGF-1 or EGF at different time points, fixed, permeabilized and stained with polyclonal antibodies directed against cortactin and the TRITC-phalloidin to stain the filamentous actin cytoskeleton. In untreated MDA-MB-231 and MCF7 cells the cortactin labeling is mainly localized in the cytoplasm, with no localization to the plasma membrane. After stimulation with IGF-1 for $10 \mathrm{~min}$ or EGF for $30 \mathrm{~min}$, MDA-MB-231 cells displayed translocation of cortactin to the plasma membrane, in areas where actin is mainly organized in ruffles and small lamellipodia (arrowheads). Similar results were obtained in MCF7 cells after treatment with IGF1 for 30 min or EGF for 10 min (arrowheads). The images are representative of three independent experiments. Bars, $10 \mu \mathrm{m}$.

subsequently stripped and blotted with anti- $\alpha$-tubulin antibody to assess the equal loading. Results showed that both the human breast cancer cell lines expressed the protein cortactin, although MCF7 cells exhibited a greater amount of the protein with respect to that expressed by MDA-MB-231 (Fig. 3A), in keeping with previous reports (36). To analyze the activation of cortactin, we performed a biochemical study of cortactin tyrosine phosphorylation in serum starved MDA-MB-231 and MCF7 cells, treated with IGF-1 or EGF at different intervals of time, as reported in Materials and methods. Immunoprecipitation with anti-cortactin antibodies and immunoblot with anti-phosphotyrosine antibody, demonstrated that in MDA-MB-231 cells both IGF-1 and EGF induced tyrosine phosphorylation of cortactin, although IGF-1 effect was already evident at $10 \mathrm{~min}$, and was still present at 30 and 60 min of stimulation (Fig. 3B, left panels). On the other hand, EGF induced a lower intensity of tyrosine phosphorylation of cortactin, with a peak of phosphorylation after 30 min of treatment (Fig. 3B, right panels). In MCF7 cells, the highest point of phosphorylation of the protein is found after $30 \mathrm{~min}$ of treatment with IGF-1, still present at $60 \mathrm{~min}$ (Fig. 3C, left panels), whereas, the treatment with EGF led to a good activation of cortactin already after $10 \mathrm{~min}$, which decreased at $30 \mathrm{~min}$ and was virtually absent after $60 \mathrm{~min}$ of stimulation (Fig. 3C, right panels). Thus, both IGF-1 and EGF were able to induce tyrosine phosphorylation of cortactin in breast cancer cells, althoug with a different intensity and kinetics, being IGF-1 stronger, faster and lasting with respect to EGF in MDA-MB-231. To analyze if the activation of cortactin in the cellular models that we assayed is dependent on Src activity, we performed parallel experiments in the presence of SU6656. The results showed that the Src inhibitor was able to block tyrosine phosphorylation of cortactin (Fig. 3B and C), as expected (37), thus suggesting a direct involvement of Src in the activation of cortactin also in our cellular models.

IGF-1 induces translocation of tyrosine phosphorylated cortactin to the plasma membrane at sites of focal adhesion. Since we have previously shown that after KGF or FGF10 treatment, cortactin translocates to the plasma membrane of human keratinocytes in areas where actin is organized in ruffles and lamellipodia (37), we wondered whether upon IGF-1 treatment the activated phosphorylated cortactin translocates to the plasma membrane also in breast cancer cells. To this purpose, we first performed immunofluorescence analysis of cortactin localization in the cellular models assayed in the present study, using polyclonal antibodies directed against cortactin and, subsequently, the TRITC-phalloidin to stain the filamentous actin cytoskeleton. Cells were treated with either IGF-1 or EGF and observed at time points in which cortactin activation has been documented to be stronger, as described in experiments shown in Fig. 3. Results demonstrated that in untreated MDA-MB231 and MCF7 cells the cortactin staining appeared mainly localized in the cytoplasm, with no localization at the plasma membrane (Fig. 4), as previously shown (37). After stimulation with IGF-1 for $10 \mathrm{~min}$ or EGF for $30 \mathrm{~min}$, MDA-MB-231 cells showed translocation of cortactin to the plasma membrane, in areas where actin is mainly organized in ruffles and lamellipodia (Fig. 4, arrowheads, left panels). Similar results were obtained in MCF7 cells after treatment with IGF-1 for $30 \mathrm{~min}$ or EGF for 10 min (Fig. 4, arrowheads, right panels). 
A

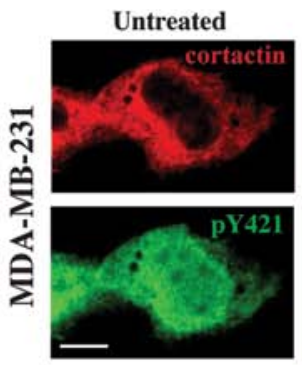

IGF-1 $10 \mathrm{~min}$

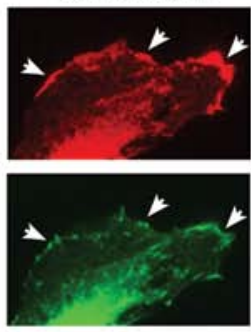

EGF 30 min
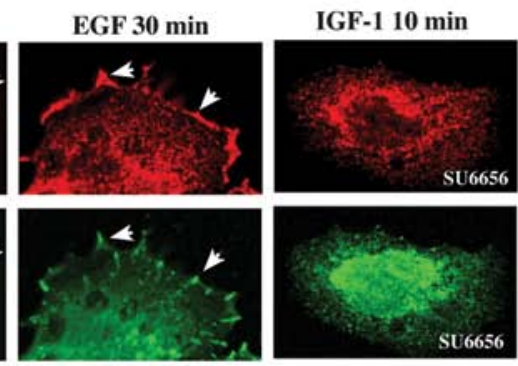

EGF $30 \mathrm{~min}$

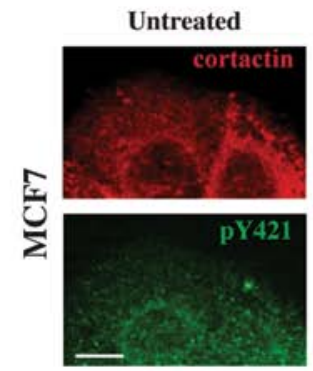

IGF-1 30 min

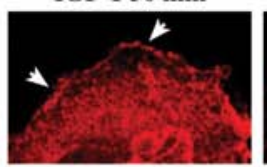

EGF $10 \mathrm{~min}$

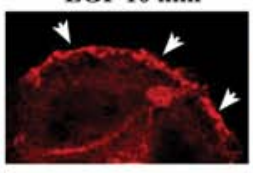

IGF-1 $30 \mathrm{~min}$

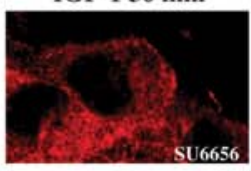

EGF 10 min
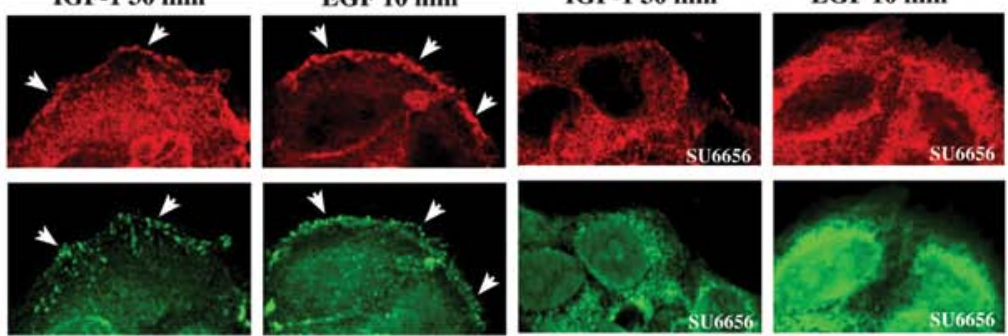

B

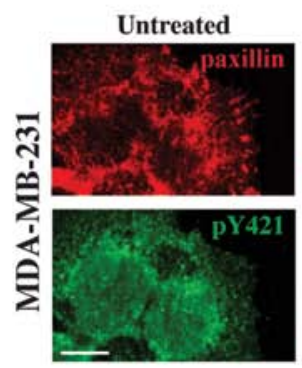

IGF-1 $10 \mathrm{~min}$

EGF $30 \mathrm{~min}$
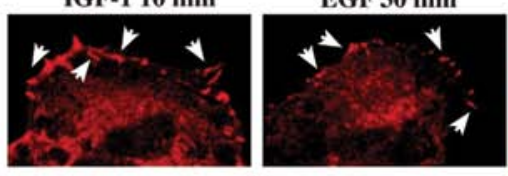

IGF-1 $10 \mathrm{~min}$

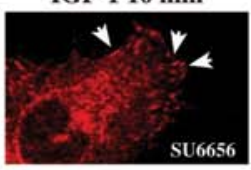

EGF $30 \mathrm{~min}$
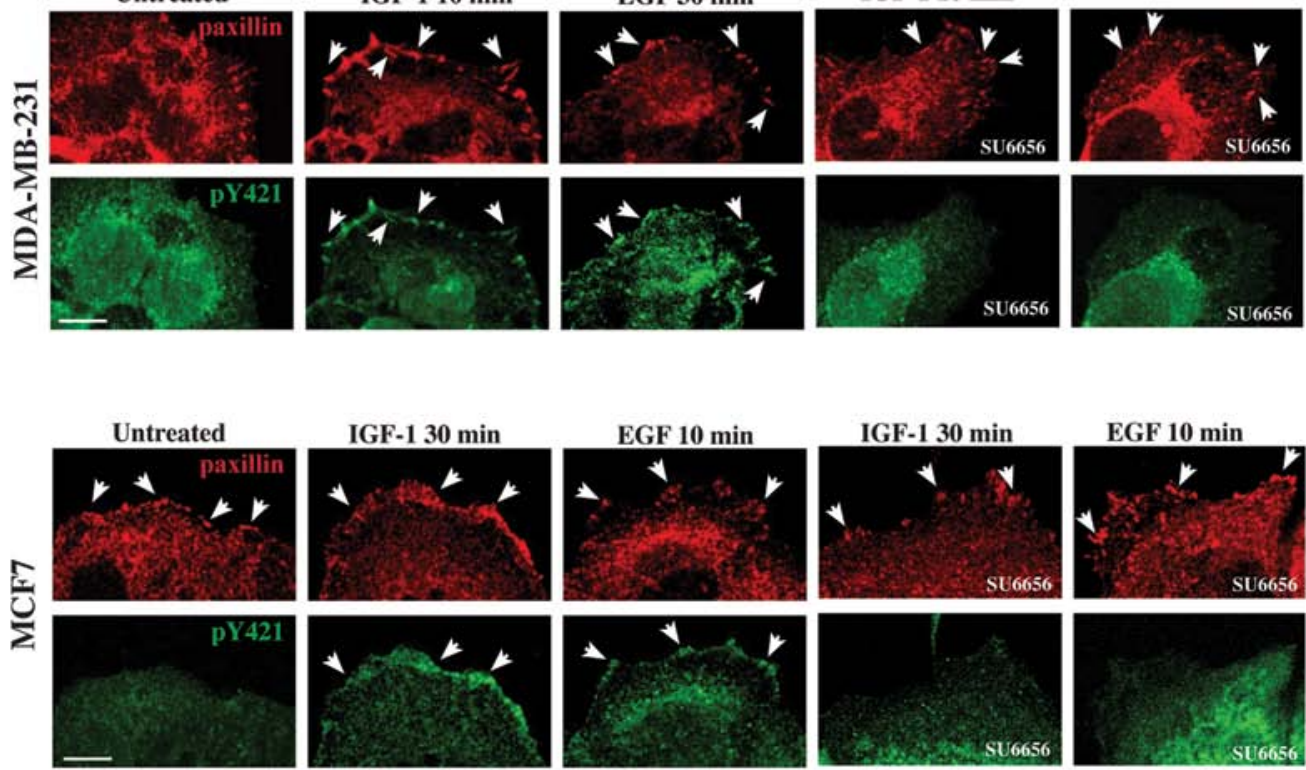

Figure 5. Phospo-cortactin localizes to the focal adhesions. (A) Serum starved MDA-MB-231 and MCF7 cells were treated with IGF-1 or EGF at different time points, fixed, permeabilized and labeled with anti-cortactin monoclonal antibody and anti-pY421 cortactin polyclonal antibodies, which specifically recognize the cortactin phosphorylated on tyrosine in position 421. Double immunofluorescence analysis show that in MDA-MB-231 cells upon stimulation with IGF-1 for 10 min or EGF for $30 \mathrm{~min}$ phospho-cortactin and cortactin colocalize on the plasma membrane (arrowheads), whereas, in untreated cells no virtual colocalization between them is evident. Upon treatment with IGF-1 for $30 \mathrm{~min}$ or EGF for $10 \mathrm{~min}$, even in the case of MCF7 cells, cortactin colocalizes with the phosphorylated form of cortactin on the plasma membrane (arrowheads), whereas no virtual colocalization is observed in untreated cells. Parallel experiments performed in the presence of SU6656 demonstrate that there are neither translocation of cortactin nor staining of phospho-cortactin on the plasma membrane. (B) Serum starved MDA-MB-231 and MCF7 cells were stimulated with IGF-1 or EGF, fixed, permeabilized and incubated with anti-paxillin monoclonal antibody to reveal paxillin, a component of the focal adhesions and with anti-pY421-cortactin to reveal the phospho-cortactin. In untreated MDA-MB-231 and MCF7 cells, paxillin staining is present on the plasma membrane (arrowheads), whereas the labeling of phospho-cortactin is not. After IGF-1 treatment for 10 min or EGF for 30 min, in MDA-MB-231 cells colocalization of phospho-cortactin with paxillin at the plasma membrane is evident (arrowheads). Similar results are obtained in MCF7 cells, upon stimulation with IGF-1 for $30 \mathrm{~min}$ or EGF for $10 \mathrm{~min}$ (arrowheads). SU6656 is able to prevent the movement of pY421 cortactin to the focal adhesions, whereas the staining of paxillin is regular (arrowheads). The images are representative of three independent experiments. Bars, $10 \mu \mathrm{m}$.

It has been shown that cortactin is phosphorylated at tyrosine residues Y421, Y466 and Y482 $(9,38)$ upon various signals, including growth factors (39), and that this occurs in a sequential manner, the tyrosine position 421 being the first to be phosphorylated, and then tyrosine 466 and finally 482 (9). In addition, cortactin phosphorylated on tyrosine 421 is found localized on lamellipodia (9). Based on these observations, we wondered whether the cortactin form that translocates to the 
plasma membrane upon IGF-1 and EGF stimulation, is the one phosphorylated on tyrosine in position 421 in our cellular models. To this purpose, we performed double immunofluorescence analysis using anti-cortactin monoclonal antibody and antipY421 cortactin polyclonal antibodies, that specifically recognize the cortactin phosphorylated on tyrosine in position 421. Results obtained showed that in MDA-MB-231 cells upon stimulation with IGF-1 for 10 min or EGF for 30 min, phospho-cortactin colocalized with cortactin on the plasma membrane, where it was translocated (Fig. 5A, arrowheads, upper panels), whereas, in untreated cells no colocalization between phosphorylated and normal cortactin was evident on the plasma membrane (Fig. 5A, upper panels). Also in MCF7 cells, after stimulation with IGF-1 for $30 \mathrm{~min}$ or EGF for $10 \mathrm{~min}$, cortactin colocalized with the phosphorylated form of the protein on the plasma membrane (Fig. 5A, arrowheads, lower panels), as previously demonstrated (40), whereas no colocalization was observed in untreated cells (Fig. 5A, lower panels). The presence of SU6656 showed that there were neither translocation of cortactin nor staining of phospho-cortactin on the plasma membrane (Fig. 5A, upper and lower panels).

Since the cortactin translocated to the plasma membrane appeared at specific sites which resembled focal adhesion, we focused our attention on paxillin, a component of focal adhesions, with a role in cell migration (41). Serum starved MDA-MB-231 and MCF7 cells were stimulated with IGF-1 or EGF, fixed, permeabilized and incubated with anti-paxillin monoclonal antibody to reveal paxillin, and with antipY421-cortactin to reveal the phospho-cortactin. In untreated MDA-MB-231 and MCF7 cells the labeling of phosphocortactin was not present at the plasma membrane (Fig. 5B, upper and lower panels), whereas the staining of paxillin was evident at the periphery of the cells (Fig. 5B, arrowheads, upper and lower panels). After IGF-1 treatment for $10 \mathrm{~min}$ or EGF for $30 \mathrm{~min}$, MDA-MB-231 cells showed an evident colocalization of phospho-cortactin with paxillin in correspondence of focal adhesions (Fig. 5B, arrowheads, upper panels). Also in the case of MCF7 cells stimulation with IGF-1 for 30 min or EGF for $10 \mathrm{~min}$ induced the localization of pY421-cortactin at the plasma membrane where paxillin was evident (Fig. 5B, arrowheads, lower panels). The presence of SU6656 inhibited the localization of pY421 cortactin to the focal adhesions, whereas the staining of paxillin was regular (Fig. 5B, arrowheads, upper and lower panels).

Taken together, these results indicate that IGF-1 and EGF were able to induce translocation of pY421-cortactin to the plasma membrane at the focal adhesions, where it colocalizes with paxillin. Moreover, the employment of SU6656 strongly suggest a direct involvement of Src in this process.

\section{Discussion}

The rationale of our investigation on IGF-1 and EGF-dependent migration and on the pathways involved in ER-negative and ER-positive breast cancer cell lines, is that the migration of cancer cells greatly contribute to their metastatic potential, that is the major clinical threat in cancer patients. Overexpression and activation of IGF-1R have been associated with some different aspects of the progression in cancer (10). Several studies indicate that in breast cancer, both IGF-1 and EGF are involved in the processes of cell adhesion, invasion and anchorage-independent growth that finally lead to the migration and metastatic spreading (19-23). Both IGF-1R and EGFR activate common downstream signaling pathways, meanly those involving MAP kinase and Akt. IGF-1R functions are predominantly mediated through IGF-1-induced activation of the phosphoinositide 3-kinase (PI3K)-AKT, RAS-RAF-MAPK and $\mathrm{p} 38$ MAPK signaling cascades (42). The cooperativity between Src and EGFR, as well as other motogenic receptors, is well established (43), and a variety of docking proteins that contain Src homology-2 (SH2) and phosphotyrosine binding (PTB) domains, bind the intracellular domains of the activated receptors (44). Our study demonstrates that both IGF-1 and EGF induce a significant effect on migration of human breast cancer cells. IGF-1 treatment of MDA-MB-231 cells resulted in significantly enhanced cell migration. The effect is earlier, stronger and steadier, when compared to the EGF and untreated control cells under the same experimental conditions. The effect of EGF, with respect to IGF-1 treatment, on ER-positive MCF7 cells in inducing cell migration is, on the contrary, greater. Our results are consistent with those obtained by Bae et al (45), who concluded that the motogenic effect of IGF-1 does not induce a motile phenotype on MCF7 cell line, and with those of Jackson et al (46), who showed that IGF-1 stimulated the migration of MDA-MB-231 cells. Moreover, we are in agreement also with Tong et al (47), who observed that EGF produced a chemoattractant effect in estrogen receptor (ER)-positive MCF-7 cells, whereas in ER-negative MDA-MB-231 breast cancer cells, EGF produced very little invasive activity.

All these observations are consistent with the view that the expression level of IGF-1R, as well as that of EGFR, are important in controlling cellular responses in terms of migration to both the growth factors. This scenario has been strenghten by the demonstration that the knockdown of the IGF-1R decreases the migration stimulated by IGF-1 in MCF7 and MDA-MB-231 cells (48).

These data strongly suggest a cell specific ability of the motogenic receptor to modulate the migratory potential of breast cancer cells. The modulation of cell motility and cell adhesion, that is essential for metastasis, arises as a result of changes in the cytoskeletal architecture $(49,50)$. Engagement or activation of cell surface growth factors and adhesion receptors affects the assembly and arrangement of F-actin networks $(51,52)$, and the cell shape. In a previous paper, DePasquale (53) showed that the treatment of MCF7 cells with estrogen induces a reorganization of the actin cytoskeleton in a complex arrangement of lamellipodia that is actively motile. In line with this report is our observation that in MCF7 cells both IGF-1 and EGF induce reorganization of actin in a large array of lamellipodia, which remains confined throughout the cell clusters and do not extend beyond the edges of the cell colonies, suggesting that the cells at the periphery of the colonies move all together along the direction of migration. Moreover, we found that MDA-MB-231 cells show typical migratory features and an evident motile phenotype upon both IGF-1 and EGF treatment, although the effect of IGF-1 is more rapid than that of EGF, reflecting the behavior of cells in terms of migration.

Cortactin has been shown to enhance lamellipodial persistence and the rate of adhesion formation in lamellipodia, consistent with an important function in regulating directed cell motility (54). As reported by Wang et al (55), we 
demonstrate that upon IGF-1 stimulation, cortactin is tyrosine phosphorylated at Y421 and translocates to the focal adhesions, where it colocalizes with paxillin. This finding may explain the observed phenotype and these changes in local F-actin dynamics may regulate cell motility.

Our data show that the inhibition of Src abolishes IGF-1- and EGF-mediated migration in both ER-positive and ER-negative cells. We demonstrated that the motogenic effect and the switch in the phosphorylation state of cortactin is Src signaling-dependent, as shown by using the selective Src-inhibitor SU6656. In our model system, MDA-MB-231 cells, which have a high invasive potential, the translocation of phospho-cortactin to the focal adhesion is IGF-1-dependent, and Src is necessary, because tyrosine phosphorylation of cortactin is linked to Src activity, as previously shown $(3,56,57)$. The initial accumulation of the post-translational activated cortactin and actin, is potentially involved in the clinical aggressiveness of both ER-positive and ER-negative breast carcinoma, because actin polymerization at the leading edge provides the protrusive force required for the extension of lamellipodia observed during cell motility and spreading (58). In agreement with Liu and Feng (59), our data suggest the Src inhibition as a potential clinical therapeutic strategy for Her2-negative breast cancer patients, but the treatment approach and the combination with chemotherapy needs to be further elucidated.

We also showed that the expression level of cortactin is different in the two cell lines, being higher in MCF7, according to their molecular subtype characteristic of luminal epithelial phenotype $(27,28)$, compared to MDA-MB-231. Our data are in agreement with a previous report in which a profile of the level of cortactin expression was assessed in a panel of breast cancer cells related to the different degree of EMS1 gene amplification (36), and with the reduced epithelial properties of MDA-MB-231 cells according to their gene expression pattern, similar to the claudin-low tumor subtype with a strong tendency to mesenchymal transition, and a low expression of genes involved in epithelial cell-cell adhesion (29). Epithelial cells are characterized by the formation of intercellular junctions, which connect and immobilize adjacent cells. Cortactin is reported to be involved in the formation of adhesion junctions after recruitment to cell-cell adhesive contacts, and it is recruited in response to homophilic cadherin ligation (60). Recently, it has been reported that inhibition of cortactin enhanced the expression of fibronectin, a specific mesenchymal marker, and accelerated TGF- $\beta 1$-induced EMT, indicating that cortactin is involved in maintaining the epithelial properties of cells (61). Based on these observations and on the results of this study, we speculate that also in our cellular models the basal level of cortactin is related to a potential function in maintaining epithelial properties in Her2-negative breast cancer cells.

In addition, we observed that cortactin is tyrosine phosphorylated by IGF-1 and EGF with different amplitude and kinetics, IGF-1 is stronger and faster than EGF in activating this protein in MDA-MB-231 cells. Whereas, in MCF7 cells, EGF-induced activation of cortactin appears to be more intense than that of IGF-1. We hypothesize that these differences in the expression, kinetics, magnitude and duration of cortactin tyrosine phosphorylation can account for the discrepancies between IGF-1 and EGF in promoting cell migration.
Collectively, our study underlines the multipotential properties of the actin-binding protein cortactin in tumor cell migration, and, in conclusion, suggests that the IGF-1/EGF-Src-cortactin pathway dependent enhancement of cell motility leads to a motile phenotype, and determines the formation of cancer cells which are migratory and invasive, hallmarks of cells that have the potential to generate metastases.

\section{Acknowledgements}

This study was funded by grant from MIUR 2009 (Ministero dell' Istruzione, dell' Università e della Ricerca).

\section{References}

1. Brooks SA, Lomax-Browne HJ, Carter TM, Kinch CE and Hall DM: Molecular interactions in cancer cell metastasis. Acta Histochem 112: 3-25, 2010

2. Bahr C and Groner B: The IGF-1 receptor and its contributions to metastatic tumor growth-novel approaches to the inhibition of IGF-1R function. Growth Factors 23: 1-14, 2005.

3. Wu H, Reynolds AB, Kanner SB, Vines RR and Parsons JT: Identification and characterization of a novel cytoskeletonassociated pp60src substrate. Mol Cell Biol 11: 5113-5124, 1991.

4. Wu H and Parsons JT: Cortactin, an 80/85-kilodalton pp60src substrate, is a filamentous actin-binding protein enriched in the cell cortex. J Cell Biol 120: 1417-1426, 1993.

5. Weed SA and Parsons JT: Cortactin: coupling membrane dynamics to cortical actin assembly. Oncogene 20: 6418-6434, 2001.

6. Daly RJ: Cortactin signalling and dynamic actin networks. Biochem J 382: 13-25, 2004.

7. Schuuring E, Verhoeven E, Litvinov S and Michalides RJ: The product of the EMS1 gene, amplified and overexpressed in human carcinoma, is homologous to a v-src substrate and is located in cell-substratum contact sites. Mol Cell Biol 13: 2891-2898, 1993.

8. Ormandy CJ, Musgrove EA, Hui R, Daly RJ and Sutherland RL: Cyclin D1, EMS1 and 11q13 amplification in breast cancer. Breast Cancer Res Treat 78: 323-335, 2003.

9. Head JA, Jiang D, Li M, Zorn LJ, Schaefer EM, Parsons JT and Weed SA: Cortactin tyrosine phosphorylation requires Rac1 activity and association with the cortical actin cytoskeleton. Mol Biol Cell 14: 3216-3229, 2003.

10. Rosenzweig SA and Atreya HS: Defining the pathway to insulin-like growth factor system targeting in cancer. Biochem Pharmacol 80: 1115-1124, 2010.

11. Surmacz E: Function of the IGF-I receptor in breast cancer. J Mammary Gland Biol Neoplasia 5: 95-105, 2000.

12. Baserga R: The IGF-I receptor in cancer research. Exp Cell Res 253: $1-6,1999$.

13. Jackson JG, White MF and Yee D: Insulin receptor substrate-1 is the predominant signaling molecule activated by insulinlike growth factor I, insulin, and interleukin-4 in estrogen receptor-positive human breast cancer cells. J Biol Chem 273: 9994-10003, 1998.

14. Schnarr B, Strunz K, Ohsam J, Benner A, Wacker J and Mayer D: Downregulation of insulin-like growth factor-I receptor and insulin receptor substrate-1 expression in advanced human breast cancer. Int J Cancer 89: 506-513, 2000.

15. Peyrat JP, Bonneterre J, Dusanter-Fourt I, Leroy-Martin B, Dijane J and Demaille A: Characterization of insulin-like growth factor 1 receptors (IGF-IR) in human breast cancer cell lines. Bull Cancer 76: 311-309, 1989.

16. Sepp-Lorenzino L, Rosen $\mathrm{N}$ and Lebwohl DE: Insulin and insulin-like growth factor signaling are defective in the MDA-MB-468 human breast cancer cell line. Cell Growth Differ 5: 1077-1083, 1994.

17. Jackson JG and Yee D: IRS-1 expression and activation are not sufficient to activate downstream pathways and enable IGF-I growth response in estrogen receptor negative breast cancer cells. Growth Horm IGF Res 9: 280-289, 1999.

18. Godden J, Leake R and Kerr DJ: The response of breast cancer cells to steroid and peptide growth factors. Anticancer Res 12: 1683-1688, 1992. 
19. Dunn SE, Ehrlich M, Sharp NJ, Reiss K, Solomon G, Hawkins R, Baserga R and Barrett JC: A dominant negative mutant of the insulin-like growth factor-I receptor inhibits the adhesion, invasion and metastasis of breast cancer. Cancer Res 58: 3353-3361, 1998.

20. Arteaga CL, Kitten LJ, Coronado EB, Jacobs S, Kull FC Jr, Allred DC and Osborne CK: Blockade of the type I somatomedin receptor inhibits growth of human breast cancer cells in athymic mice. J Clin Investig 84: 1418-1423, 1989.

21. Doerr ME and Jones J1: The roles of integrins and extracellular matrix proteins in the insulin-like growth factor I-stimulated chemotaxis of human breast cancer cells. J Biol Chem 271: 2443-2447, 1996.

22. Schlessinger J: Cell signaling by receptor tyrosine kinases. Cell 103: 211-225, 2000

23. Arteaga CL: Epidermal growth factor receptor dependence in human tumors: more than just expression? Oncologist 4: 31-39, 2002.

24. Davidson NE, Gelmann EP, Lippman ME and Dickson RB Epidermal growth factor receptor gene expression in estrogen receptor-positive and negative human breast cancer cell lines. Mol Endocrinol 1: 216-223, 1987.

25. Mamot C, Drummond DC, Greiser U, Hong K, Kirpotin DB, Marks JD and Park JW: Epidermal growth factor receptor (EGFR)-targeted immunoliposomes mediate specific and efficient drug delivery to EGFR- and EGFRvIII-overexpressing tumor cells. Cancer Res 63: 3154-3161, 2003.

26. Callahan R and Hurvitz S: Human epidermal growth factor receptor-2-positive breast cancer: current management of early, advanced, and recurrent disease. Curr Opin Obstet Gynecol 23 . 37-43, 2011.

27. Fillmore CM and Kuperwasser C: Human breast cancer cell lines contain stem-like cells that self-renew, give rise to phenotypically diverse progeny and survive chemotherapy. Breast Cancer Res 10: R25, 2008.

28. Charafe-Jauffret E, Ginestier C, Monville F, Finetti P, Adélaïde J, Cervera N, Fekairi S, Xerri L, Jacquemier J, Birnbaum D and Bertucci F: Gene expression profiling of breast cell lines identifies potential new basal markers. Oncogene 25: 2273-2284, 2006

29. Prat A,Parker JS, Karginova O,Fan C,Livasy C, Herschkowitz JI, $\mathrm{He} \mathrm{X}$ and Perou CM: Phenotypic and molecular characterization of the claudin-low intrinsic subtype of breast cancer. Breast Cancer Res 12: R68, 2010

30. Blake RA, Broome MA, Liu X, Wu J, Gishizky M, Sun L and Courtneidge SA: SU6656, a selective Src family kinase inhibitor, used to probe growth factor signaling. Mol Cell Biol 20: 9018-9027, 2000.

31. Dittmar T, Husemann A, Schewe Y, Nofer JR, Niggemann B Zanker KS and Brandt BH: Induction of cancer cell migration by epidermal growth factor is initiated by specific phosphorylation of tyrosine 1248 of c-erbB-2 receptor via EGFR. FASEB J 16: $1823-1825,2002$

32. Hirsch DS, Shen Y and Wu WJ: Growth and motility inhibition of breast cancer cells by epidermal growth factor receptor degradation is correlated with inactivation of $\mathrm{Cdc} 42$. Cancer Res 66: 3523-3530, 2006.

33. Playford MP and Schaller MD: The interplay between Src and integrins in normal and tumor biology. Oncogene 23 . 7928-7946, 2004.

34. Ridley AJ, Schwartz MA, Burridge K, Firtel RA, Ginsberg MH, Borisy G, Parsons JT and Horwitz AR: Cell migration: integrating signals from front to back. Science 302: 1704-1709, 2003

35. Azios NG and Dharmawardhane SF: Resveratrol and estradiol exert disparate effects on cell migration, call surface actin structures, and focal adhesion assembly in MDA-MB-231 human breast cancer cells. Neoplasia 7: 128-140, 2005.

36. Campbell DH, deFazio A, Sutherland RL and Daly RJ: Expression and tyrosine phoshorylation of EMS1 in human breast cancer cell lines. Int J Cancer 68: 485-492, 1996.

37. Ceccarelli S, Cardinali G, Aspite N, Picardo M, Marchese C, Torrisi MR and Mancini P: Cortactin involvement in the keratinocyte growth factor and fibroblast growth factor 10 promotion of migration and cortical actin assembly in human keratinocytes. Exp Cell Res 313: 1758-1777, 2007.

38. Huang C, Liu J, Haudenschild CC and Zhan X: The role of tyrosine phosphorylation of cortactin in the locomotion of endothelial cells. J Biol Chem 273: 25770-25776, 1998.
39. Weed SA, Du Y and Parsons JT: Translocation of cortactin to the cell periphery is mediated by the small GTPase Rac1. J Cell Sci 111: 2433-2443, 1998.

40. Ren G, Helwani FM, Verma S, McLachlan RW, Weed SA and Yap AS: Cortactin is a functional target of E-cadherin-activated Src family kinases in MCF7 epithelial monolayers. J Biol Chem 284: 18913-18922, 2009.

41. Brown MC and Turner CE: Paxillin: adapting to change. Physiol Rev 84: 1315-1339, 2004

42. Vincent AM and Feldman EL: Control of cell survival by IGF signaling pathways. Growth Horm IGF Res 12: 193-197, 2002.

43. Biscardi JS, Tice DA and Parsons SJ: c-Src, receptor tyrosine kinases, and human cancer. Adv Cancer Res 76: 61-119, 1999.

44. Ravichandran KS: Signaling via Shc family adapter proteins. Oncogene 20: 6322-30, 2001.

45. Bae SN, Arand G, Azzam H, Pavasant P, Torri J, Frandsen TL and Thompson EW: Molecular and cellular analysis of basement membrane invasion by human breast cancer cells in matrigelbased in vitro assays. Breast Cancer Res Treat 24: 241-255, 1993.

46. Jackson JG, Zhang X, Yoneda T and Yee D: Regulation of breast cancer cell motility by insulin receptor substrate-2 (IRS-2) in metastatic variants of human breast cancer cell lines. Oncogene 20: 7318-7325, 2001

47. Tong GM, Rajah TT and Pento JT: The differential influence of EGF, IGF-I and TGF-beta on the invasiveness of human breast cancer cells. In Vitro Cell Dev Biol Anim 36: 493-494, 2000.

48. de Blaquiere GE, May FE and Westley BR: Increased expression of both insulin receptor substrates 1 and 2 confers increased sensitivity to IGF-1 stimulated cell migration. Endocr Relat Cancer 16: 635-647, 2009.

49. Lester BR and McCarthy JB: Tumor cell adhesion to the extracellular matrix and signal transduction mechanisms implicated in tumor cell motility, invasion and metastasis. Cancer Metastasis Rev 11: 31-44, 1992.

50. Yamaguchi H, Pixley F and Condeelis J: Invadopodia and podosomes in tumor invasion. Eur J Cell Biol 85: 213-218, 2005.

51. Zigmond SH: Signal transduction and actin filament organization. Curr Opin Cell Biol 8: 66-73, 1996.

52. Schoenwaelder SM and Burridge K: Bidirectional signaling between the cytosckeleton and integrins. Curr Opin Cell Biol 11: 274-286, 1999.

53. DePasquale JA: Rearrangement of the F-actin cytoskeleton in estradiol-treated MCF7 breast carcinoma cells. Histochem Cell Biol 112: 341-350, 1999.

54. Bryce NS, Clark ES, Leysath JL, Currie JD, Webb DJ and Weaver AM: Cortactin promotes cell motility by enhancing lamellipodial persistence. Curr Biol 15: 1276-1285, 2005.

55. Wang W, Liu Y and Liao K: Tyrosine phosphorylation of cortactin by the FAK-Src complex at focal adhesions regulates cell motility. BMC Cell Biol 13: 12-49, 2011.

56. Mader CC, Oser M, Magalhaes MA, Bravo-Cordero JJ, Condeelis J, Koleske AJ and Gil-Henn H: An EGFR-SrcArg-Cortactin pathway mediates functional maturation of invadopodia and breast cancer cell invasion. Cancer Res 71: 1730-1741, 2011.

57. Artym VV, Zhang Y, Seillier-Moiseiwitsch F, Yamada KM and Mueller SC: Dynamic interactions of cortactin and membrane type 1 matrix metalloproteinase at invadopodia: defining the stages of invadopodia formation and function. Cancer Res 66: 3034-3043, 2006.

58. Small JV and Resch GP: The comings and goings of actin: coupling protrusion and retraction in cell motility. Curr Opin Cell Biol 17: 517-523, 2005.

59. Liu X and Feng R: Inhibition of epithelial to mesenchymal transition in metastatic breast carcinoma cells by c-Src suppression. Acta Biochim Biophys Sin (Shanghai) 42: 496-501, 2010.

60. Helwani FM, Kovacs EM, Paterson AD, Verma S, Ali RG, Fanning AS, Weed SA and Yap AS: Cortactin is necessary for E-cadherin-mediated contact formation and actin reorganization. J Cell Biol 164: 899-910, 2004.

61. Zhang K, Wang D and Song J: Cortactin is involved in tranforming growth factor-betal-induced epithelial-mesenchymal transition in AML-12 cells. Acta Biochim Biophys Sin (Shanghai) 41: 839-845, 2009. 